\title{
Extension of Intersection Method for Multi-Objective Optimization in Case of Interval Number and its Application
}

\author{
Maosheng Zheng*, Yi Wang, Haipeng Teng
}

\begin{abstract}
This paper aims to develop the extension of intersection method for multi-objective optimization under condition of interval number. Based on the linear correlation of partial favourable probability and the corresponding performance indicator, and the assumption of uniform distribution of the actual value of performance indicator within the range of its lower and upper limits in case of interval number, it derives that the actual partial favourable probability of a performance indicator is the arithmetic mean value of the partial favourable probabilities of the arithmetic mean value and the variation value of the interval index of the corresponding performance indicator for each candidate, or their desired sum. Furthermore, according to the rule of algorithm for the total favourable probability quantitatively, all candidates are ranked according to their total favourable probabilities to complete the multi- objective optimization in case of interval number. As applications, the quantitative assessments of multi-criteria selections for effective dwelling house walls, project managers and contractor for construction works are given in detail, satisfied results are obtained.
\end{abstract}

Keywords: arithmetic mean; favourable probability; intersection method; interval number; multi-objective optimization

\section{INTRODUCTION}

Multi-objective optimization (MOO) is the process of specifying the optimal solution from all feasible alternatives. The category of MOO is to conduct the selection from a limited number of alternatives by assessing the performances of multiple objects in beneficial or non - beneficial manners comparatively. A MOO technique determines how the performance information to be assessed and to get the appropriate selection. Given the proper decision matrix and decision-making procedures, the decision maker could conduct the best alternative and /or rank to complete the selection.

In traditional multi - objective optimizations, the performance indexes and attributes are assumed to be well determined without any uncertainty. However, in some cases, the responses of alternatives to attribute are not always possessing exact values. Especially, decision makers' judgment is often vague, which may not present their preferences with exact numerical values. In order to deal with such uncertain elements of a decision problem, several approaches are proposed. In interval COPRAS-G, complex steps are included involving artificial parameters and personality [1]. Hafezalkotob et al. extended the MULTIMOORA method to include interval number by using fuzzy logic theory and a novel comparison technique [2], by introducing a preferences of $A \geq B$ or $B \geq A$, and each coordinate of the comparison matrix of $P_{q r}$ being a one - to one comparison between intervals, as well as specific value of 0.5 for diagonal preferences, i.e., $\left\{P_{11}, P_{22}, \ldots, P_{v v}\right\}$. Jahanshahloo et al. proposed an extension of the technique for order preference by similarity to ideal solution (TOPSIS) to deal with decision making problems with interval numbers [3]. Sayadi et al. extended the VIse Kriterijumska Optimizacija i kompromisno Resenje (VIKOR) technique by considering interval value [4]. Pan et al. formulated an interval multi attribute decision making (MADM) approach by using the linear additive utility function and composite utility variance [5]. Chen et al. developed a unique interval MADM method with loss aversion [6]. Cao and Wu extended the continuous ordered weighted geometric (COWG) operators to solve multiple attributive group decision making (MAGDM) problems with interval numbers [7]. Brauers et al. employed the fuzzy numbers to extend the crisp MULTIMOORA method [8]. Liu et al. utilized fuzzy numbers to determine the risk of failure modes by extending MULTIMOORA method [9]. Mandal and Sarkar used the fuzzy MOORA methodology to perform the selection of an optimal intelligent manufacturing system [10].

Recently, a new "intersection" method for MOO was proposed in the viewpoints of probability theory and set theory [11], which aims to solve the inherent problems of personal and subjective factors in previous multi - object optimizations. In the new MOO method, a novel concept of favourable probability was developed, which reflects the favourable degree of the candidate in the optimization; each performance utility indicator of the candidate contributes to a partial favourable probability quantitatively; the total favourable probability of a candidate is the product of all partial favourable probabilities in the viewpoint of probability theory, which is the overall and unique decisive index in the competitive selection process. The new MOO method was applied in materials selection and multi objective orthogonal test design (MOOTD) and multi objective uniform test design (MOUTD) successfully [11].

As a further study on the newly proposed "intersection" method for MOO, here in this paper, an extension of the intersection method for MOO under condition of interval indexes is developed so as to include this case in the evaluations.

\section{EXTENSION OF THE "INTERSECTION" METHOD FOR MOO IN CASE OF INTERVAL NUMBER}

In traditional MOO, the performance indexes and attributes are assumed to be well determined without any uncertainty. However, in some cases, the performance indexes and attributes are often vague, which results in unexact numerical values instead of well determined data. In 
order to deal with such decision problem with uncertain elements, proper approach is in need.

In general, the decision-making matrix $X$ is with the form of Eq. (1) in case of interval numbers,

$$
X=\left[\begin{array}{l}
{\left[w_{11} ; b_{11}\right]\left[w_{12} ; b_{12}\right] \cdots\left[w_{1 m} ; b_{1 m}\right]} \\
{\left[w_{21} ; b_{21}\right]\left[w_{22} ; b_{22}\right] \cdots\left[w_{2 m} ; b_{2 m}\right]} \\
\cdots\left[w_{i j} ; b_{i j}\right] \cdots \\
{\left[w_{n 1} ; b n 1\right]\left[w_{n 2} ; b_{n 2}\right] \cdots\left[w_{n m} ; b_{n m}\right]}
\end{array}\right]
$$

$i=1,2, \ldots, n ; j=1,2, \ldots, m$.

In Eq. (1), $w_{i j}$ represents the lower limit, and $b_{i j}$ is the upper limit of the performance index.

The main feature of the new "intersection" method for $\mathrm{MOO}$ is that there is no necessary to make normalization for the decision-making matrix [11], the partial favourable probability can be obtained from the decision-making matrix directly for the performance index with exact value, and the total favourable probability is the overall representative in the viewpoint of probability theory, which is the unique decisive index in the competitive selection process.

However, in some cases there gives the interval value instead of exact value for the performance index, i.e., the lower limit and upper limit of the performance indicator.

In cases of interval values, it is no doubt that the value of the performance index is within the range of the lower and upper limits of the performance indicator. Thus the lower and upper limits of the performance indicator may lead to uncertainty of the partial favorable probability of the performance index.

In [11], it assumed that the partial favourable probability is correlative to the corresponding performance index linearly from the principle of simplicity, if we further assume that the actual value of the performance indicator under condition of interval number is uniformly distributed within the range of its lower and upper limits, then the actual partial favourable probability of a performance index is the arithmetic mean value of the partial favourable probabilities of the arithmetic mean value $m_{i j}=\left(w_{i j}+b_{i j}\right) / 2$ and the variation value $v_{i j}=\left(b_{i j}-w_{i j}\right) / 2$ of the interval index, i.e. or their desired sum,

$P_{i j}=\frac{\left[P\left(m_{i j}\right)+P\left(v_{i j}\right)\right]}{2}$, or

$P_{i j}=a_{j} * P\left(m_{i j}\right)+\left(1-a_{j}\right) * P\left(v_{i j}\right)$.

In Eq. (2), $P\left(m_{i j}\right)$ and $P\left(v_{i j}\right)$ represent the partial favorable probabilities of the arithmetic mean value and variation value of the interval index, respectively. The assessments of $P\left(m_{i j}\right)$ and $P\left(v_{i j}\right)$ are in accordance with Ref. [11], individually; in general, $P\left(v_{i j}\right)$ is attributed to non-beneficial type; $a_{j}$ is the adjust parameter for desired sum.

In this operation, the interval index is divided into two parts, i.e., $m_{i j}$ and $v_{i j}$, which represent the various properties of interval index in different aspects. This operation opens a new treatment to interval index, which breaks away from the persecution of comparison of interval indexes, while the comparison of interval indexes is continuously an unsolvable problem.

Afterwards, the assessment of the intersection method for MOO under condition of interval number will be as usual as that in [11].

Till now, the extension of intersection method for multi - objective optimization under condition of interval number is completed.

\section{APPLICATIONS OF THE EXTENSION OF INTERSECTION METHOD FOR MULTI-OBJECTIVE OPTIMATION}

In this section, the extended intersection method for MOO in case of interval number is applied to deal with the following multi-criteria decision-making problems.

\subsection{Selection for Effective Dwelling House Walls}

Zavadskas et al. once developed a "specific method of multiple criteria decision-making combining with grey relations" to deal with the problem of attribute values within intervals [1]. Tab. 1 shows the initial decision-making index for effective dwelling house walls with values expressed in intervals, which is cited from [1].

Table 1 Initial decision-making matrix with values expressed in intervals

\begin{tabular}{|c|c|c|c|c|c|c|c|c|c|c|}
\hline $\begin{array}{c}\text { Alternate } \\
\text { No. }\end{array}$ & \multicolumn{2}{|c|}{ Durability } & \multicolumn{2}{|c|}{$\begin{array}{l}\text { Thermal } \\
\text { transmit. }\end{array}$} & \multicolumn{2}{|c|}{ Cost } & \multicolumn{2}{|c|}{$\begin{array}{l}\text { Weight } \\
\text { of wall }\end{array}$} & \multicolumn{2}{|c|}{$\begin{array}{c}\text { Human } \\
\text { expenditure }\end{array}$} \\
\hline Weight $q$ & \multicolumn{2}{|c|}{0.21} & \multicolumn{2}{|c|}{0.33} & \multicolumn{2}{|c|}{0.26} & \multicolumn{2}{|c|}{0.09} & \multicolumn{2}{|c|}{0.11} \\
\hline Index & \multicolumn{2}{|c|}{$X_{1}$} & \multicolumn{2}{|c|}{$X_{2}$} & \multicolumn{2}{|c|}{$X_{3}$} & \multicolumn{2}{|c|}{$X_{4}$} & \multicolumn{2}{|c|}{$X_{5}$} \\
\hline Optimum & \multicolumn{2}{|c|}{$\max$} & \multicolumn{2}{|c|}{$\min$} & \multicolumn{2}{|c|}{$\min$} & \multicolumn{2}{|c|}{$\min$} & \multicolumn{2}{|c|}{$\min$} \\
\hline Alternat. & $w_{1}$ & $b_{1}$ & $w_{2}$ & $b_{2}$ & $w_{3}$ & $b_{3}$ & $w_{4}$ & $b_{4}$ & $w_{5}$ & $b_{5}$ \\
\hline$A_{1}$ & 75 & 100 & 0.22 & 0.25 & 72.08 & 94.71 & 590 & 652 & 4.60 & 4.60 \\
\hline$A_{2}$ & 75 & 100 & 0.22 & 0.25 & 89.01 & 100.93 & 596 & 625 & 4.60 & 4.60 \\
\hline$A_{3}$ & 75 & 100 & 0.21 & 0.25 & 80.32 & 96.42 & 581 & 604 & 4.60 & 4.60 \\
\hline$A_{4}$ & 25 & 25 & 0.24 & 027 & 67.76 & 98.10 & 455 & 479 & 4.55 & 5.01 \\
\hline
\end{tabular}

Table 2 Evaluated results for actual partial favourable probability, total favourable probability and ranking

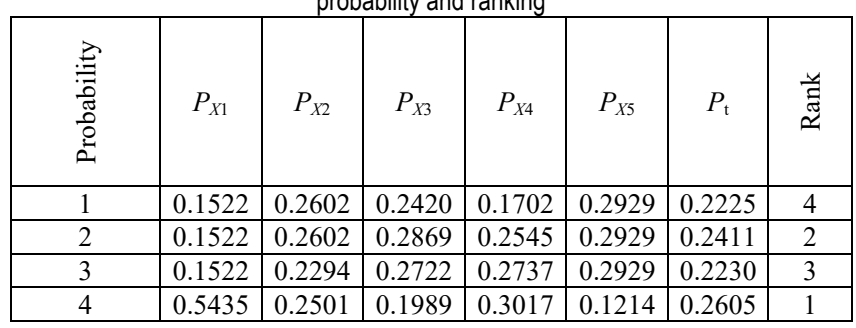

In Tab. $1, b_{i j}$ means the upper limit of the $j$ performance indicator in the $i$ alternative of a solution, $w_{i j}$ means the lower limit of the $j$ performance indicator in the $i$ alternative of a solution; the word "max" in Tab. 1 means "the higher the better", i.e., beneficial performance index, and the word "min" means "the lower the better", i.e., unbeneficial performance index in the multi-objective optimization evaluation for the arithmetic mean value of the interval index.

The partial favourable probabilities of $P\left(m_{i j}\right)$ and $P\left(r_{i j}\right)$ are assessed from the performance data of the interval indexes shown in Tab. 1. According to Eq. (2), the arithmetic mean value of the partial favourable probabilities of 
performance indexes of the candidates of mean value and variation represents the actual partial favourable probabilities of performance indicators, which is shown in Tab. 2.

The evaluated results for total favourable probability together the ranking results are given in Tab. 2 as well.

The sequence in Tab. 2 is " $A_{4}>A_{2}>A_{3}>A_{1}$ ", which is not the same as the ranking of Zavadskas [1], however one may use the formula of desired sum with adjust parameter $\alpha_{j}$ to improve the consequence for one's aim; the expression " $A_{4}$ $>A_{2}$ " here means that $A_{4}$ is prior to $A_{2}$.

\subsection{Multi-Criteria Selection of Project Managers}

In addition, in Ref. [12], Zavadskas et al. applied the "specific method of multiple criteria decision-making combining with grey relations" to deal with a project manager problem.

Tab. 3 shows the initial decision-making index for project manager problem, which is cited from [12].

Table 3 Initial decision-making index with the criterion values described in intervals

\begin{tabular}{|c|c|c|c|c|c|c|c|c|c|c|c|c|}
\hline Index & \multicolumn{2}{|c|}{$X_{1}$} & \multicolumn{2}{|c|}{$X_{2}$} & \multicolumn{2}{|c|}{$X_{3}$} & \multicolumn{2}{|c|}{$X_{4}$} & \multicolumn{2}{|c|}{$X_{5}$} & \multicolumn{2}{|c|}{$X_{6}$} \\
\hline Optimum & \multicolumn{2}{|c|}{$\max$} & \multicolumn{2}{|c|}{$\max$} & \multicolumn{2}{|c|}{$\max$} & \multicolumn{2}{|c|}{$\max$} & \multicolumn{2}{|c|}{$\max$} & \multicolumn{2}{|c|}{$\min$} \\
\hline Weight $q$ & \multicolumn{2}{|c|}{0.25} & \multicolumn{2}{|c|}{0.15} & \multicolumn{2}{|c|}{0.12} & \multicolumn{2}{|c|}{0.20} & \multicolumn{2}{|c|}{0.13} & \multicolumn{2}{|c|}{0.15} \\
\hline Manager & $\underline{x_{1}}$ & $\bar{x}_{1}$ & $\underline{x_{2}}$ & $\bar{x}_{2}$ & $\underline{x}_{3}$ & $\bar{x}_{3}$ & $\underline{x}_{4}$ & $\bar{x}_{4}$ & $\underline{x}_{5}$ & $\bar{x}_{5}$ & $\underline{x}_{6}$ & $\bar{x}_{6}$ \\
\hline 1 & 50 & 60 & 40 & 55 & 10 & 20 & 50 & 70 & 45 & 50 & 30 & 40 \\
\hline 2 & 70 & 80 & 60 & 70 & 40 & 45 & 60 & 75 & 70 & 80 & 60 & 70 \\
\hline 3 & 60 & 70 & 55 & 70 & 30 & 40 & 70 & 80 & 55 & 65 & 40 & 50 \\
\hline
\end{tabular}

In Tab. $3, \bar{x}_{i j}$ means the upper limit of the $j$ attribute in the $i$ alternative of a solution, $\underline{x}_{i j}$ means the lower limit of the $j$ attribute in the $i$ alternative of a solution.

Again, let's using Eq. (2) to conduct the assessment of the actual partial favourable probabilities for the performance indicators, the results are shown in Tab. 4.

Tab. 4 shows evaluated results for total favourable probability and ranking as well.

Table 4 Evaluated results for partial favourable probability, total favourable probability and ranking for project manager selection

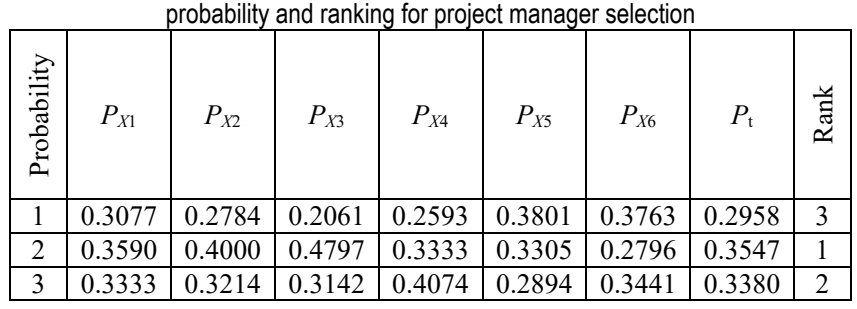

The sequence in Tab. 4 is "project manager $2>$ project manager $3>$ project manager $1 "$, which is the same as the ranking in [12] fortuitously.

\subsection{Multi-Criteria Selection of Contractor for Construction Works}

Beside, in Ref. [13], Zavadskas et al. studied contractor selection problem for construction works by applying saw-g and TOPSIS grey techniques.
Tab. 5 shows the initial decision-making index values of contractor selection for construction works problem, which is cited from [13].

Table 5 Initial decision-making index values of contractor selection for construction works problem

\begin{tabular}{|c|c|c|c|c|c|c|c|c|c|c|c|c|}
\hline Index & \multicolumn{1}{|c|}{$X_{1}$} & \multicolumn{2}{|c|}{$X_{2}$} & \multicolumn{2}{|c|}{$X_{3}$} & \multicolumn{2}{c|}{$X_{4}$} & \multicolumn{2}{|c|}{$X_{5}$} & \multicolumn{2}{c|}{$X_{6}$} \\
\hline Optimum & \multicolumn{2}{|c|}{$\max$} & \multicolumn{2}{c|}{$\max$} & \multicolumn{2}{c|}{$\max$} & \multicolumn{2}{c|}{$\min$} & \multicolumn{2}{c|}{$\max$} & \multicolumn{2}{c|}{$\max$} \\
\hline Alternative & $w_{1}$ & $b_{1}$ & $w_{2}$ & $b_{2}$ & $w_{3}$ & $b_{3}$ & $w_{4}$ & $b_{4}$ & $w_{5}$ & $b_{5}$ & $w_{6}$ & $b_{6}$ \\
\hline$A_{1}$ & 11 & 15 & 10 & 15 & 3.30 & 4.5 & 35 & 48 & 0.152 & 0.203 & 1 & 2 \\
\hline$A_{2}$ & 10 & 14 & 7 & 13 & 2.54 & 3.68 & 40 & 58 & 0.111 & 0.162 & 1 & 2 \\
\hline$A_{3}$ & 14 & 18 & 5 & 9 & 1.95 & 2.46 & 42 & 53 & 0.079 & 0.121 & 1 & 3 \\
\hline$A_{4}$ & 12 & 16 & 1 & 4 & 0.42 & 1.73 & 15 & 63 & 0.01 & 0.054 & 1 & 2 \\
\hline$A_{5}$ & 6 & 10 & 2 & 9 & 0.62 & 2.67 & 10 & 46 & 0.012 & 0.122 & 1 & 2 \\
\hline
\end{tabular}

Once more, Eq. (2) is used to conduct the assessment of the actual partial favourable probabilities for the performance indicators, the results are shown in Tab. 6.

Tab. 6 shows evaluated results for total favourable probability and ranking of each candidate as well.

Table 6 Evaluated results for partial favorable probability, total favorable probability and ranking of contractor selection for construction works problem

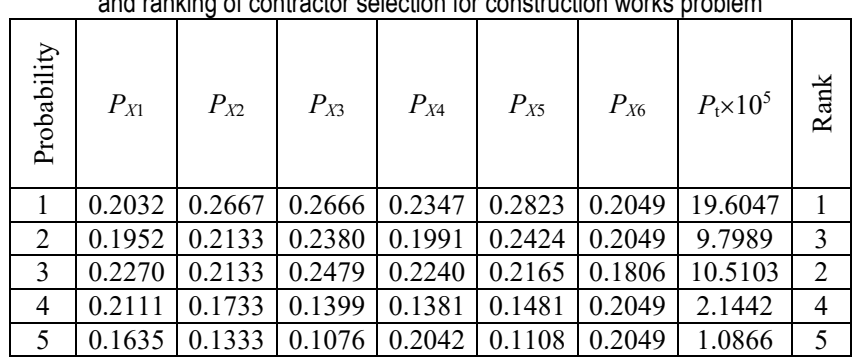

The sequence in Tab. 6 is " $A_{1}>A_{3}>A_{2}>A_{4}>A_{5}$ ", which is not the same as the ranking in [13].

The applications of the extension of new method for MOO under condition of interval number by above cases indicate its validity.

\section{CONCLUSION}

From above discussion, the extension of the new method for multi-objective optimization in case of interval number is an appropriate approach. The arithmetic mean value of the partial favourable probabilities of arithmetic mean value and variation value of the interval index or their desired sum gives the actual value of the partial favourable probabilities of the corresponding performance indexes. The total favourable probability is the overall and unique indicator to decide the final result of the assessment comprehensively. The approach is full probability theory based, which is categorical and simple without any artificial and personal factors.

\section{Conflict Statement}

There is no conflict of interest. 


\section{REFERENCES}

[1] Zavadskas, E. K., Kaklauskas, A., Turskis, Z., \& Tamošaitien, J. (2008). Selection of the effective dwelling house walls by applying attributes values determined at intervals. Journal of Civil Engineering and Management, 14(2), 85-93. https://doi.org/10.3846/1392-3730.2008.14.3

[2] Hafezalkotob, A., Hafezalkotob, A., \& Kazem Sayadi, M. (2016). Extension of MULTIMOORA method with interval numbers: An application in materials selection. Applied Mathematical Modelling. 40, 1372-1386. https://doi.org/10.1016/j.apm.2015.07.019

[3] Jahanshahloo, G. R., Lotfi, F. H., \& Izadikhah, M. (2006). An algorithmic method to extend TOPSIS for decision-making problems with interval data. Appl. Math. Comput. 175, 13751384. https://doi.org/10.1016/j.amc.2005.08.048

[4] Sayadi, M. K., Heydari, M., \& Shahanaghi, K. (2009). Extension of VIKOR method for decision making problem with interval numbers. Appl. Math. Model. 33, 2257-2262. https://doi.org/10.1016/j.apm.2008.06.002

[5] Pan, J., Teklu, Y., Rahman, S., \& de Castro, A. (2000). An interval-based MADM approach to the identification of candidate alternatives in strategic resource planning. IEEE Trans. Power Syst. 15, 1441-1446. https://doi.org/10.1109/59.898125

[6] Chen, F. D., Zhang, X., Kang, F., Fan, Z., \& Chen, X. (2010). A method for interval multiple attribute decision making with loss aversion. Proceedings of the 2010 International Conference of Information Science and Management Engineering (ISME), Xian, Shaanxi, China, 453-456. https://doi.org/10.1109/ISME.2010.155

[7] Cao, Q.-W. \& Wu, J. (2011). The extended COWG operators and their application to multiple attributive group decision making problems with interval numbers. Appl. Math. Model. 35, 2075-2086. https://doi.org/10.1016/j.apm.2010.11.040

[8] Brauers, W. K. M., Baležentis, A., \& Baležentis, T. (2011). MULTIMOORA for the EU Member States updated with fuzzy number theory. Technol. Econ. Dev. Econ. 17, 259-290. https://doi.org/10.3846/20294913.2011.580566

[9] Liu, H.-C., Fan, X.-J., Li P., \& Chen, Y.-Z. (2014). Evaluating the risk of failure modes with extended MULTIMOORA method under fuzzy environment. Eng. Appl. Artif. Intell. 34, 168-177. https://doi.org/10.1016/j.engappai.2014.04.011

[10] Mandal, U. K. \& Sarkar, B. (2012). Selection of best intelligent manufacturing system (IMS) under fuzzy MOORA conflicting MCDM environment. Int. J. Emerg. Technol. Adv. Eng. 2, 2250-2459.

[11] Zheng, M., Wang, Y., \& Teng, H. (2021). A New "Intersection" Method for Multi-Objective Optimization in Material Selection. Tehnicki Glasnik, 15(4), 526-528. https://doi.org/10.31803/tg- 20210901142449

[12] Zavadskas, E. K., Turskis, Z., Tamošaitiene, J. \& Marina, V. (2008). Multicriteria selection of project managers by applying grey criteria. Technological and Economic Development of Economy, 14(4), 462-477. https://doi.org/10.3846/1392-8619.2008.14.462-477

[13] Zavadskas, E. K., Vilutiene, T., Turskis, Z. \& Tamosaitiene, J. (2010). Contractor selection for construction works by applying saw-g and topsis grey techniques. Journal of Business Economics and Management, 11(1), 34-55. https://doi.org/10.3846/jbem.2010.03
Authors' contacts:

Maosheng Zheng

(Corresponding author)

School of Chemical Engineering, Northwest University,

No. 229, Taibai North Road, Xi'an, 710069, Shaanxi Province, China

E-mail: mszhengok@aliyun.com

\section{Yi Wang}

School of Chemical Engineering, Northwest University,

No. 229, Taibai North Road, Xi'an, 710069, Shaanxi Province, China

\section{Haipeng Teng}

School of Chemical Engineering, Northwest University,

No. 229, Taibai North Road, Xi'an, 710069, Shaanxi Province, China 